\title{
O IEA: da "Pré-História" à História
}

\section{CARLOS GUILHERME MOTA ${ }^{I}$}

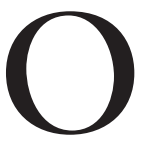

INSTITUTO de Estudos Avançados (IEA) começou a nascer no dia 20 de fevereiro de 1986, quando o recém-eleito reitor José Goldemberg convidou-me para auxiliá-lo na criação da nova unidade na Universidade de São Paulo. Enorme desafio, pois sabíamos das dificuldades para mudar-se qualquer coisa na universidade, engessada e hiperburocratizada após o período ditatorial. Muitas foram as discussões e tentativas que nos antecederam, capitaneadas por professores como Erney Camargo Plessman, Crodowaldo Pavan, Alberto Luís da Rocha Barros, José Jeremias de Oliveira, e mais uma dezena de colegas. A ideia de um Instituto, a exemplo do de Princeton, que recebeu Einstein e outros exilados, sempre esteve no ar, para acolher mestres como Mário Schenberg, Florestan Fernandes, Vilanova Artigas, e muitos outros.

Indicado pela comunidade de alunos, funcionários e alguns professores, eu disputara as eleições para a Reitoria. Embora no ano anterior tivesse sido eleito para a direção da Faculdade de Filosofia e vetado pelo reitor Guerra Vieira, logo percebi que a viabilidade de minha candidatura era quase nula. Passei a apoiar na lista tríplice os nomes de Goldemberg, Dallari e Caio Dantas. Mais preparado e experiente para o posto, o físico Goldemberg, mais votado, foi escolhido pelo governador Franco Montoro, que lhe deu suporte financeiro e administrativo. Iniciava-se o processo de abertura da USP, coarctado alguns anos mais tarde.

Dado que a criação de um IEA e de um Centro de Estudos do Terceiro Mundo constava de minha proposta como candidato, fui convidado pelo novo reitor a coordenar dois grupos de estudos para criá-los. Para o Centro de Estudos sobre o Terceiro Mundo convidei Antonio Candido, Milton Santos, Darcy Ribeiro, mas nossos esforços foram em vão. Já o IEA, antiga aspiração de muitos, teve melhor receptividade, contando a comissão com o grupo inicial composto por Alberto Carvalho da Silva, Rocha Barros, Roberto Lobo (vice-reitor), por mim coordenado. ${ }^{1}$ Sem ouvir o Conselho Universitário, rapidamente como é de seu feitio, Goldemberg baixou portaria criando o Instituto. "Se eu levar a proposta para aprovação do Conselho ela não passa...”, comentou. E logo nomeou um Conselho Diretor composto por mim como diretor, Gerhard Malnic, ativo vice-diretor, Alfredo Bosi, José Galizia Tundisi, Moysés Nussensweig, Paul Singer e, como membro ativo da sociedade civil, o financista/colunista do Estadão, Geraldo de Figueiredo Forbes. 
Após inúmeras consultas a especialistas e intelectuais da USP, logo desenhamos nosso IEA, resguardando a interdisciplinaridade, a rotatividade da direção e do Conselho Diretor, a presença da sociedade civil e fixando nossos objetivos gerais, que incluíam a publicação de uma revista inter e muldisciplinar de alto nível, a Estudos Avançados, hoje em seu n.89. Para definir nosso perfil inspiramo-nos nos estatutos do Collège de France, do Colegio de Mexico, da École des Hautes Études en Sciences Sociales (Paris), da Casa de las Americas (Cuba), dos Institutos de Estudos Avançados de Princeton e de Berlim, do Centro de Estudos Sociais de Moçambique (Maputo), cientes, porém, de que não estávamos nem em Princeton nem em Maputo ${ }^{2} \ldots$

Claro estava para nós que a criação do IEA constituía um desdobramento dos esforços anteriores para sua existência, em que se destacaram, além dos já citados, os cientistas Ernst Hamburguer, Rocha Barros, Crodowaldo Pavan, cujas aspirações procuramos honrar. Curioso, um dia perguntei ao reitor Goldemberg por que escolhera um historiador para a direção, dado que havia tantos cientistas envolvidos. Respondeu-me que o país necessitava mais de historiadores para saber de onde veio e para onde vai...

Foi nessa perspectiva que escolhemos o jurista e historiador Raymundo Faoro para fazer, no dia 25 de agosto de 1986, apresentado pelo professor Antonio Candido, a densa e longa conferência inaugural na sala do Conselho Universitário sobre o tema "Existe um pensamento político brasileiro?". A sala lotada do Conselho se desburocratizava, todos animados a aplaudir a análise apresentada, durante três horas e meia pelo jurista. Nascia o Instituto!

Por que Faoro? Porque produzira uma obra clássica de grande abrangência e altitude, Os donos do poder, Formação do patronato politico brasileiro, e também porque se tratava de espírito eminentemente interdisciplinar; e ainda porque suas obra e ação estavam voltadas à construção de uma nova sociedade civil no país. Poderíamos acrescentar: não possuía os títulos universitários, exceto o de bacharel em Direito. "Sou um simples advogado", dizia. E isso nos interessava também, pois o IEA não deveria ser mais uma fábrica de títulos. Ao pensar assim abrimos espaço e demos voz a intelectuais como José Paulo Paes e Jacó Gorender...

O texto de Faoro inaugurava também o ${ }^{\circ} 1$ da revista Estudos Avançados (hoje em seu número 89), junto com artigo do historiador Michel Vovelle, da Sorbonne, sobre o Bicentenário da Revolução Francesa, e um dossiê sobre a criação do IEA.

Ainda em 1986, no dia 27 de novembro, o economista John Kenneth Galbraith veio falar, a convite do reitor, sobre "O controle de armamentos e o poder militar". Outros conferencistas do mês foram Florestan Fernandes (que iniciou sua conferência indagando-nos em quê o IEA era "avançado"?...), William Saad Hossne, Erney Camargo, Dalmo Dallari, Gerhard Malnic, Boaventura de Sousa Santos... 
Desde o início, a Diretoria criara duas atividades contínuas: a Conferência do Mês, dada por especialistas reconhecidos, e o Café Acadêmico, reuniões semi-informais com pesquisadores dos grupos de pesquisa e visitantes sobre questões relevantes. Nessa atividade, cumpríamos também um de nossos objetivos principais, qual seja, o de congregar, em reuniões abertas, pesquisadores, professores, diplomatas e jornalistas, políticos, além de empresários e líderes dos trabalhadores.

Já nas reuniões do Conselho em março de 1986, definimos algumas áreas do conhecimento a serem cultivadas no IEA. Dois pilares iniciais, a área de História das Ideologias e Mentalidades, que coordenei com Alfredo Bosi, contando com Michel Debrun, Octavio Ianni, Enrique Amayo Zevallos, Marlise Meyer e, mais tarde, José Paulo Paes (depois professor visitante); e a área de Economia e Política, coordenada por Paul Singer e Lourdes Sola, que promoveriam o importante Simpósio Internacional "Democratizing Economics: Discourse and praxis", em associação com o historiador Richard Morse, do Wilson Center, o qual retornaria como visiting scholar ao nosso Instituto. Logo foram aprovadas pelo Conselho outras áreas, como Biologia Molecular (coordenada por Moisés Nussensweig); Ciências Ambientais (por J. G. Tundisi); e Relações e Políticas Externas (coordenada por Jacques Marcovitch, com Geraldo F. Forbes e outros). O IEA também participou de eventos laterais, como o Colóquio "1789Luzes e Sombras", coordenado por Renato Janine Ribeiro. E, em associação com os historiadores Katia Mattoso e François Crouzet, da Sorbonne, o Congresso Centenário da República.

Outros grupos seriam implantados, como Economia da Biotecnologia (coordenado por Hernan Chaimovich); Lógica e Filosofia da Ciência (coordenado por Newton da Costa, com Pablo Mariconda e Jair Minoru Abe); Política Científica e Tecnológica (coordenado por Erney Camargo, com Gerhard Malnic, Eunice Durham, Jacques Marcovitch e Simon Schwartzman, depois professor visitante); O Psíquico nos Territórios do Social (coordenado por Norberto Abreu e Silva, com os professores Bento Prado Júnior, Silvia Leser, Zeljko Loparic, Isaias Mehlson, entre outros); Museus e Universidade (coordenado por Ana Mae Barbosa e Maria Cristina Bruno); e o ativo núcleo Educação e Constituinte, criado para discutir propostas à Constituinte, coordenado por Alfredo Bosi, com os professores Celso Beisigel, Demerval Saviani, Amélia Hamburguer, Shigueo Watanabe, dando origem ao Grupo de Educação Paideia.

Grupos inovadores foram criados, apoiando-se na pequena estrutura e no competente staff do IEA, como o de Arquitetura e Urbanismo, coordenado por Nestor Goulart Reis, composto pelos professores Milton Santos, Maria Adélia de Sousa, Celso Lamparelli. E, em convênio com a França, o Banco de Dados Brasil-França, coordenado por Leyla Perrone-Moysés e Helena Bonito, delineando sólido projeto no campo digital. 
Apesar da escassez de meios e de pessoal, o IEA conseguiu trazer à luz dois programas notáveis: o extraordinário Projeto Floram, (1989, com Leopoldo Rodes, W. Zulauf, Ab'Saber, Marcovitch, Goldemberg et al.) que marcou época (http://www.scielo.br/scielo.php?script=sci_arttext\&pid =S0103-40141990000200002); e o projeto de Revisão Constitucional (1993, com Geraldo Forbes e Bolivar Lamounier) que, com a cooperação de mais de 20 grandes juristas, economistas, cientistas políticos etc. ofertou ao Congresso Nacional, para discussão, uma completa Revisão da Constituição de 1988. Foi o IEA/USP simplesmente o único centro gerador de ideias que produziu uma proposta revisional integral...

Todo o staff sempre foi marcante na vida do IEA. Na implantação, a competente administradora cultural Claudia Toni, secretária acadêmica, criou normas e fixou nosso ethos institucional, rompendo com a tradição burocrático-uspiana. O historiador Edgard Luís de Barros trouxe-nos seu ativismo crítico acelerado. Vários jovens pesquisadores se aproximaram do Instituto, como Ricardo Medrano, físico e arquiteto, e Carlos Leite, arquiteto. Mais tarde, os competentes jornalistas Dario Luis Borelli, depois editor da revista Estudos Avançados, e Mauro Bellesa, na Comunicação.

Respeitados professores visitantes trouxeram ares novos ao ambiente da USP, como os historiadores Manuel Moreno Fraginals, primeiro cubano a atuar na USP, o peruano Aníbal Quijano e o norte-americano Richard Morse que, apesar de decano dos "so called brazilianists", jamais fora convidado a visitar a USP. Presenças marcantes foram também as de Boaventura de Sousa Santos, que aqui escreveu Introdução a uma Ciência Pósmoderna, do músico Hans-Joachim Koellreutter, do matemático Jean Louis Koszul (discutindo o grupo Bourbaki), do historiador Jacob Gorender, do escritor e tradutor José Paulo Paes, da ativista portuguesa dos Direitos Humanos Ana Vicente, do economista e ex-ministro Luís Carlos Bresser-Pereira. Da USP, foram incorporados ao Instituto os Professores Eméritos Aziz Ab'Saber e Ruy Coelho, que deixaram valiosas contribuições.

Dentre os grandes conferencistas no IEA, citem-se o professor Florestan Fernandes, o ator Paulo Autran, William Saad Hossne, Jurgen Habermas, José Saramago, o angolano Luandino Vieira, o futuro presidente da Itália Giorgio Napolitano, o futuro presidente do Brasil Fernando Henrique Cardoso, Eduardo Portella, Maria Isaura Pereira de Queirós, Alfred Stepan, Dionísio Toledo, Bolivar Lamounier, Leopoldo de Meis, Ivan Izquierdo, Barbara Freitag, os historiadores Kenneth Maxwell, Eric J. Hobsbawm, Warren Dean, Cristopher Hill, Alberto da Costa e Silva, António Pedro Vicente, Carlo Ginzburg, Laura de Mello e Souza, Marc Ferro, Katia Mattoso, François Crouzet...

Um dos "segredos" do êxito do IEA foi a existência de um poder informal paralelo, o "Senado Invisível", composto por cerca de 40 colegas de vários quadrantes, adeptos de nosso projeto, frequentadores e formuladores de propostas 
levadas ao Conselho Diretor. Dele participaram ou participam pesquisadores como Walter Colli, Caio Dantas, Eunice Durham, Ruth Cardoso, Sergio Mascarenhas, Walnice N. Galvão, J. R. Carvalheiro, Gabriel Cohn, e personalidades como Severo Gomes, a historiadora Lêda Boechat Rodrigues (que doou ao IEA a biblioteca sua e de José Honório Rodrigues, hoje no Instituto de Estudos Brasileiros (IEB)), Paulo Nogueira Batista e Marco Antonio Coelho, por muitos anos editor executivo da revista.

Algumas outras instituições tiveram origem ou o apoio do IEA. Uma foi o Memorial da América Latina (por solicitação de Darcy Ribeiro e Antonio Candido, coordenei as primeiras reuniões, com Bosi, Octavio Ianni, Aracy Amaral, Amayo Zevallos). Outra foi a Cátedra Jaime Cortesão, inaugurada pelo historiador Fernando Catroga, de Coimbra. Esta que foi a nossa primeira Cátedra, fundada com o apoio da Casa de Portugal, do Conselho das Comunidades Portuguesas de São Paulo e da Comissão dos Descobrimentos de Lisboa, depois passou para a Faculdade de Filosofia, Letras e Ciências Humanas (FFLCH-USP). O ex-deputado Fernando Leça, membro do Conselho das Comunidades, foi decisivo nessa frutuosa colaboração.

Três razões do sucesso do Instituto: o empenho de um reitor com visão ampla e crítica, experiência internacional e capacidade decisória; a diversidade de formação e competência dos diretores, asseguradores de bom clima intelectual para convivência crítica; e a sempre cuidadosa seleção na composição dos Conselhos Diretores com personalidades efetivamente universitárias.

Em 1988 assumiu a direção o professor Jacques Marcovitch, dando continuidade aos projetos, estruturando melhor a administração do Instituto e ampliando horizontes, sobretudo no campo das relações internacionais e na problemática do meio ambiente. Em sua gestão, a revista Estudos Avançados se consolidou como referência acadêmica. E na gestão do diretor João Steiner subiu ao Scielo e entrou no mundo digital.

Enfim, no Instituto de Estudos Avançados, instituição modelar, vivi minha mais desafiadora e prazerosa experiência universitária. Um privilégio!

São Paulo, 14 de setembro de 2016

\section{Notas}

1 Registre-se que o professor Antonio Candido, já aposentado, fora convidado pelo reitor para dirigir o Instituto, mas não aceitou, colocando-se, entretanto, como "soldado" para a consolidação do projeto. Efetivamente, participou de várias iniciativas e, consultado, indicou o nome do professor Alfredo Bosi para integrar nosso Conselho Diretor.

$2 \mathrm{O}$ Estatuto só foi redigido e aprovado alguns anos depois da fundação. Cf. nosso artigo "Nem Princeton nem Maputo", na revista Estudos Avançados, n.3, v.2, 1988. 
Carlos Guilherme Mota foi diretor do Instituto de Estudos Avançados da USP no período de 1986-1988. É professor emérito da Faculdade de Filosofia, Letras e Ciências Humanas da USP, professor titular de História da Cultura da FAU-Mackenzie, e membro do Núcleo de Estudos Avançados da Universidade Presbiteriana Mackenzie. @ - cgsmota@terra.com.br

Recebido em 14.9.2016 e aceito em 15.10/2016.

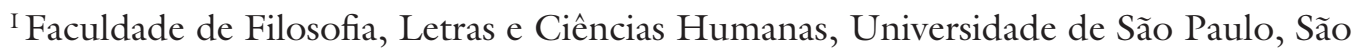
Paulo/São Paulo, Brasil. 